parity, a symmetry that ultimately helps to account for the preponderance of matter over antimatter in the Universe, is in the study of neutral kaon mesons, a declaration that will not be popular with those working on certain experiments based in the United States and Japan.

The main thrust of the final part of the book is the exploration of physics in those often exotic places where both quantum mechanics and gravity play a role, such as at the birth of the Universe or in the vicinity of a black hole. The very existence of the second law of thermodynamics is used to argue that the Universe must have started out in an extraordinarily special configuration (something else that will be familiar to readers of The Emperor's New Mind), which Penrose takes as a hint that the quantum theory requires revision.

After a more detailed discussion of the measurement paradox, Penrose is ready to expound his belief that quantum state reduction is an objective process, arising as a consequence of the gravitational energy difference between the different space-time geometries possessed by quantum states in superposition. By now, Penrose is becoming increasingly partisan, although he is careful to announce when he is deviating from the "accepted wisdom". He is forceful in stating his objections to several mainstream ideas: inflationary cosmology, low-energy supersymmetry, the electroweak phase transition and string theory are all targets. Indeed, his presentation of string theory is essentially a technical critique, and I suspect it will be inaccessible to non-experts. At times his objections can lead to rather judgemental and acerbic statements: the leading string theorist, Ed Witten, is described at one point as a "tour guide".

Having been so critical, Penrose offers his thinking on the possible way forward for a consistent theory of quantum gravity. Unfortunately these two chapters are the most challenging of the whole book. Loop variables, spin networks and his own twistor theory are all presented, although he acknowledges that these ideas have not yet come close to matching up as a viable physical theory.

In sum, this book certainly doesn't live up to the publisher's hype. It is too technical to be accessible to a general audience and is focused on only one branch of modern science. However, it is carefully crafted and rich in deep insight. Penrose's own hand drawings help to remind the reader of the very personal account provided in its pages. Penrose, leading by example, clearly intends that this book should encourage scientists to dare to be original in their quest: in that, he may well have succeeded.

Jeffrey Forshaw is in the Department of Physics and Astronomy, University of Manchester,

Oxford Road, Manchester M13 9PL, UK.

\section{Field guides and phylogenies}

\section{Flowers of Ethiopia and Eritrea: \\ Aloes and Other Lilies \\ by Sebsebe Demissew, Inger Nordal \& \\ Odd E. Stabbetorp \\ Shama Books, Addis Ababa, Ethiopia: 2004. \\ 227 pp. US $\$ 15$}

e-mail: shamabooks@telecom.net.et

\section{Sandra Knapp}

Taxonomy has been much in the news in the past year or so. Everybody seems to want more of it, and in a slightly different way than it is currently done. Perhaps taxonomy should be done solely on the web, or by using a set of DNA barcodes - opinions differ. But just what is taxonomy and why is it suddenly in demand? I contend that taxonomy (or systematics, as some people prefer to call it) is composed of three interlocking spheres of scientific endeavour: phylogeny, description and identification. This book is a sterling example of how all three aspects of taxonomy can come together to produce something of lasting value to a variety of end-users.

The book is a colour guide to the identification of the charismatic flowers that characterize dry habitats such as Ethiopia 'lilies' in the broadest sense. Identification is aided by easy-to-use keys, simple descriptions and lovely photographic plates, which make this a nice book for just exploring the amazing diversity of these plants, quite apart from its obvious use in the field. But the authors have done more than just produce an identification guide: they have set the lilies of the region in their phylogenetic context, and the book's introduction shows just how important it is to link those three areas of taxonomic study.

The phylogeny of the monocots (such as lilies, grasses and orchids) has undergone radical change and restructuring with the use of DNA sequence data. The number of families recognized and their relationships to one another have changed considerably over the past decade (see Bot. J. Linn. Soc. 141, 399-436; 2003). Rather than brushing all this under the carpet, the authors clearly and concisely explain why phylogeny matters. Then, through the use of the field-guide format, they show how such rearrangements make sense when looking at the plants themselves. They are also brave enough to admit what all taxonomists know: that the classification of such groups, where new data are emerging, is still in flux.

Phylogenies and field guides are both of obvious use, but both require a solid base of descriptive taxonomy. This book, and to a certain extent the phylogeny to which it adheres, rests on the descriptive work done on the region's flora. Major projects documenting national floras (and faunas) have uncovered new species and provided the observations and taxonomic decisions that are needed for both phylogeny and field identification.

Books such as this, with its numerous illustrations and accessible style, inspire others to study organisms, helping the accumulation of information about uses and, to my mind more importantly, conservation status. How on earth can we conserve biodiversity unless we know something about it? This book is an example of how to do it.

Sandra Knapp is in the Department of Botany, The Natural History Museum, Cromwell Road, London SW7 5BD, UK.

\section{Sculpture}

\section{Opening time}

On a summer evening several years ago, Eduardo Catalano, emeritus professor of architecture at the Massachusetts Institute of Technology, watched a flower as it was starting to close its petals. Suddenly, he realized what the movable structure he had so long wanted to create should look like.

That moment of inspiration resulted in 13 months of construction work. The outcome was Floralis Genérica, a stunning, gigantic flower (right) made of an aluminium alloy covered in stainless steel, intended to represent all flowers. It is 20 metres high and weighs 18 tons. Each of its six petals is 13 metres long and 7 metres wide, and they are mounted on a conical structure. A computer-controlled hydraulic mechanism opens the flower at sunrise and closes it at dusk. Red light is projected on the inner surface of the petals when the flower closes.

Born in Argentina, Catalano donated the

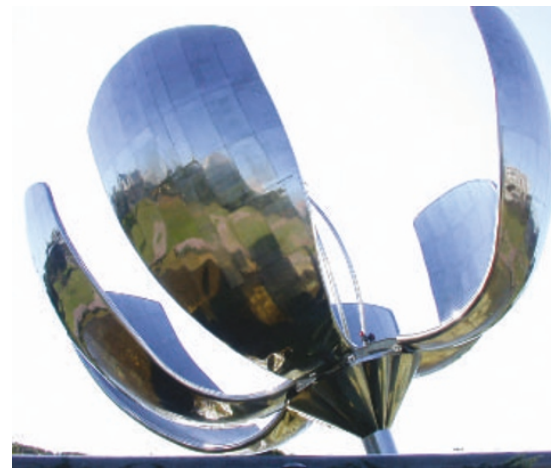

flower to the city of Buenos Aires, where it was inaugurated in April 2002. Floralis Genérica has found its home in a large pond in the heart of the city. The flower is kept open round the clock on the first day of spring and on some public holidays. And whenever there is a new Moon such as today. 